\title{
Pemanfaatan Penginjeksian Elektron Sebagai Upaya Penghematan Bahan Bakar Bensin Pada Kendaraan Bermotor
}

\author{
Ida Bagus Dharmawan, Riswan Asmaran, Yudi Kurniawan \\ Jurusan Teknik Mesin Alat Berat \\ Politeknik Negeri Balikpapan \\ Jl. Soekarno Hatta Km.8 Balikpapan Tlp. (0542) 860895 Fax. 861107 \\ Email : bagus.belvalina@gmail.com
}

\begin{abstract}
This study is an engineering injection tool electrons in the input fuel flow. The tool was tested saving performance in motor vehicle fuel use. This study was a single factor (giving the voltage on the input fuel flow) done in completely randomized design with 3 levels of treatment, ie, 0 volts, 12 volts and 16 volts, each performed with four replications. The length of the input fuel flow pipe engineering tools tested were 24 that were attempted in motorcycle brands Honda Astrea Impressa gasoline in 1998. Later the use of different voltages on fuel saving devices with fuel flow pipe length of $24 \mathrm{~cm}$ gives a significant effect on fuel consumption in motor vehicles.
\end{abstract}

Keywords: electron injection, fuel consumption, fuel flow.

\section{Abstrak}

Penelitian ini merupakan sebuah rekayasa alat penginjeksian elektron pada input aliran bahan bakar. Alat tersebut diuji kinerjanya dalam menghematan penggunaan bahan bakar kendaraan bermotor. Penelitian ini merupakan penelitian faktor tunggal (pemberian tegangan pada aliran input bahan bakar) yang dilakukan dalam rancangan acak lengkap dengan 3 level perlakuan, yaitu, 0 volt, 12 volt dan 16 volt, masing-masing dilakukan dengan 4 ulangan. Panjang pipa aliran input bahan bakar alat rekayasa yang diuji adalah 24 yang dicobakan pada sepeda motor merk Honda Astrea Impressa tahun 1998 berbahan bakar bensin. Kemudian dalam penggunaan tegangan yang berbeda pada alat penghemat bahan bakar dengan panjang pipa aliran bahan bakar $24 \mathrm{~cm}$ memberikan pengaruh nyata terhadap konsumsi penggunaan bahan bakar pada kendaraan bermotor.

Kata Kunci : Injeksi elektron, konsumsi bahan bakar, aliran bahan bakar

\section{Pendahuluan}

Pembangunan yang berkembang pesat dewasa ini, khususnya dalam industri dan teknologi, serta meningkatnya jumlah kendaraan bermotor yang pada umumnya menggunakan bahan bakar fosil (minyak) menyebabkan persediaan dari bahan bakar yang ada didunia semakin menipis.

Minyak bumi (petroleum) adalah campuran yang kompleks, terutama terdiri dari hidrokarbon bersama-sama dengan sejumlah kecil komponen yang mengandung sulfur, oksigen dan nitrogen dan sangat sedikit komponen yang mengandung logam. Minyak bumi bahasa Inggris petroleum, dari bahasa Latin petrus - karang dan oleum - minyak), dijuluki juga sebagai emas hitam, adalah cairan kental, coklat gelap, atau kehijauan yang mudah terbakar, yang berada di lapisan atas dari beberapa area di kerak Bumi. Minyak bumi terdiri dari campuran kompleks dari berbagai hidrokarbon, sebagian besar seri alkana, tetapi bervariasi dalam penampilan, komposisi, dan kemurniannya

Minyak bumi terbentuk sebagai hasil akhir dari penguraian bahan-bahan organik (sel-sel dan jaringan hewan/tumbuhan laut) yang tertimbun selama berjuta tahun di dalam tanah, baik di daerah daratan atau pun di daerah lepas pantai. Hal ini menunjukkan bahwa minyak bumi merupakan sumber daya alam yang tidak dapat diperbaharui. Terbentuknya minyak bumi sangat lambat, oleh karena itu perlu penghematan dalam penggunaannya. 
Upaya menghemat penggunaan bahan bakar yang diakibatkan oleh bahan bakar bensin terus dilakukan. Bukan hanya perubahan pada mekanisme mesin kendaraan bermotor tetapi juga teknologi bahan bakar terus dikembangkan sampai dengan pembakaran pada ruang bakar (cumbustion chamber). Upaya lain dapat juga dilakukan dengan cara mengganti bahan bakar yang sudah ada dengan bahan bakar alternatif-alternatif yang lebih ramah lingkungan dan hemat bahan bakar. Salah satu upaya yang dilakukan pada tulisan ini adalah menjadikan pembakaran bahan bakar bensin lebih sempurna pada ruang bakar dengan terikatnya secara baik molekul-molekul bahan bakar. Upayaupaya itu dapat dilihat dari berbagai jenis nama produk bahan bakar saat ini seperti dibawah ini.

Namun saat ini berdasarkan keluhan masyarakat yang merujuk pada kenaikan harga BBM (bahan bakar minyak) saat ini. Kami berusaha untuk menemukan solusi dari salah satu masalah masyarakat ini, yaitu dengan cara menemukan cara atau metode yang dapat membuat konsumsi bahan bakar pada kendaraan bermotor menjadi lebih efisien dan lebih irit. Langkah yang akan ditempuh untuk membuat bahan bakar menjadi irit adalah dengan penyempurnaan pada proses pembakaran bahan bakar di ruang bakar diantaranya adalah percobaan pada atomatom yang terkandung pada bahan bakar. Berkenaan dengan hal itu penulis tertarik membahas hal ini dengan harapan pada perpindahan elektron-elektron bahan bakar bensin dengan proses mengaktifkan aliran arus DC dan pemberian tahanan yang berbeda dipipa masuk aliran bahan bakar dapat terjadi perpindahan elektron arus DC dengan elektron-elektron yang terdapat pada bahan bakar bensin maka diharapkan terjadi pembakaran yang sempurna pada ruang bakar dan memberikan penggunaan bahan bakar menjadi lebih efisien dan irit.

Berdasarkan uraian tersebut diatas sehingga perlu dilakukan upaya penelitian untuk mencari cara penghematan penggunaan bahan bakar pada kendaraan bermotor yang menggunakan bahan bakar bensin. Hal-hal yang dapat dilakukan dalam mengupayakan penghematan bahan bakar yang salah satunya adalah penyempurnaan pada proses pembakaran bahan bakar pada ruang bakar. Percobaan yang dilakukan dengan pemberian elektronelektron pada atom-atom yang terkandung pada bahan bakar dapat mengakibatkan terjadinya ikatan senyawa bensin secara sempurna.

Laporan Penelitian ini membahas pengaruh pemberian elektron-elektron pada aliran suplai bahan bakar bensin dengan proses mengaktifkan aliran arus DC dengan menggunakan dua macam pipa masuk aliran bahan bakar dengan panjang berbeda. Penelitian ini berguna untuk meningkatkan proses pembakaran sempurna pada ruang bakar sehingga dapat menghemat dalam penggunaan bahan bakar.

\section{Metoda Penelitian}

Metoda Penelitian yang digunakan tersebut meliputi:

1. Waktu dan Tempat

Penelitian ini merupakan penelitian eksperimen yang dilakukan di Workshop Teknik Mesin Alat Berat Politeknik Negeri Balikpapan. Penelitian dilakukan selama 5 bulan.

\section{Alat dan Bahan}

Bahan- bahan yang digunakan :

a. Bahan bakar gasoline (Bensin)

b. Majun

c. Oli Mesin

Alat-alat yang digunakan :

a. 1 Unit Sepeda Motor Astrea Grand th 1998 (Karbulator, 4 langkah, pendingin udara, 100 cc)

b. Tool kits

c. Battery (accu) $12 \mathrm{~V}$

d. Rangkaian aliran Arus DC.

e. Rangkaian Rancangan Alat Perpindahan Elektron

f. Rangkaian Potensiometer

g. Multimeter 


\section{h. Tabung Indicator Penggunaan bahan bakar}

1. Rangkaian Penghemat Bahan Bakar.

Rancang Bangun alat sumber tegangan pada aliran bahan bakar disajikan pada Gambar 3. Tegangan yang diberikan pada aliran input bahan bakar diharapkan mampu mempengaruhi efisiensi penggunaan bahan bakar melalui proses perpindahan elektron-elektron pada bahan bakar.

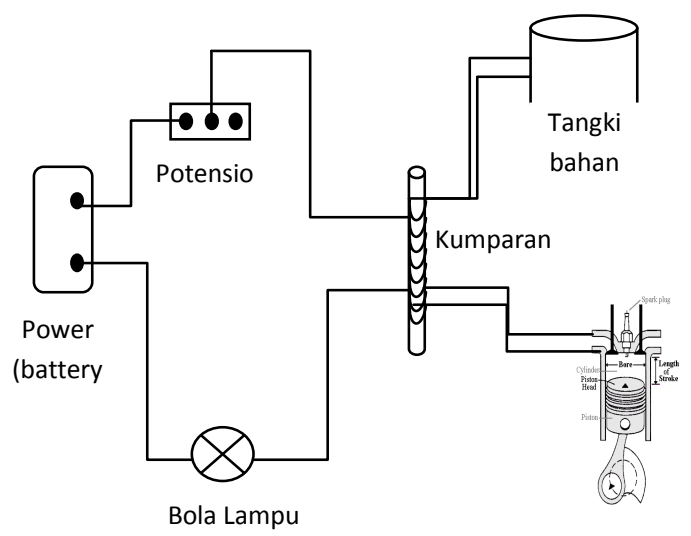

Gambar 3.1. Rancangan bangun alat sumber tegangan

2. Rancangan Penelitian

Penelitian ini akan dilakukan dalam rancangan acak lengkap faktor tunggal, yaitu besar tegangan (V) pada aliran input bahan bakar dengan panjang $24 \mathrm{~cm}$. Level perlakuan yang akan digunakan adalah

1. Pengaturan tegangan dengan media potensio

a. Tegangan pada Kumparan : 0 volt

b. Tegangan pada Kumparan : 12 volt

c. Tegangan pada Kumparan : 16 volt

2. Pengaturan Jumlah bahan bakar yang digunakan masing-masing level perlakuan dilakukan dengan 5 ulangan.

3. Prosedur Penelitian

Penelitian dilaksanakan dengan kondisi-kondisi yang telah ditetapkan sebagai acuan yaitu : Penyetelan standart pada sepeda motor terutama pada karburator yang diberikan tegangan yang berbeda. Kemudian dicatat berapa jumlah penggunaan bahan bakarnya, pada saat sebelum diberikan tegangan dan setelah diberikan tegangan.

Prosedur pengujian

1) Memasukkan kendaraan ke ruang uji.

2) Mempersiapkan kendaraan untuk penguji

- Menentukan panjang lintasan yang ditempuh sebesar 2200 meter per pengujian

- Menentukan kecepatan rata-rata sepeda motor $30 \mathrm{KM} / \mathrm{jam}$

- Memastikan kendaraan berada pada temperature kerja (autodata). Apabila belum, maka lakukan pemanasan kendaraan sebelum memulai langkah berikutnya.

- Mematikan semua peralatan tambahan. Pastikan mesin tidak menerima beban tambahan.

- Memastikan choke dalam keadaan tidak bekerja.

3) Melakukan pengujian dengan tegangan 0 volt.

4) Melakukan perhitungan jarak yang ditempuh pada kendaraan yang telah di isi dengan bahan bakar 1 liter.

5) Mempersiapkan pengujian yang kedua dan ketiga dengan menambah tegangan yang diberikan menjadi $12 \mathrm{~V}$ dan $16 \mathrm{~V}$, kemudian catat hasil perbedaan jarak yang dapat di tempuh

\section{Hasil dan Pembahasan}

Hasil penelitian ini memberikan data pengaruh pemberian voltase pada aliran suply bahan bakar kendaraan bermotor merk Honda Astrea Impressa tahun 1998 bahan bakar bensin terhadap hasil penghematan bahan bakar. Data yang disajikan dari hasil pengujian dengan pemberian elektron-elektron pada aliran bahan bakar dilakukan dengan level perlakuan 0 volt, 12 volt dan 16 volt. dengan ulangan 5 kali menggunakan rancangan rekayasa panjang aliran bahan bakar yaitu $24 \mathrm{~cm}$.

Untuk memastikan ketelitian pada hasil pengujian sehingga perlu dilakukan pengecekan beberapa kondisi pada 
peralatan dan lingkungan sekitar. Data kondisi lingkungan dan kendaraan pada saat pengujian adalah sebagai berikut :

\begin{tabular}{|c|c|c|c|c|c|}
\hline Ulangan & $\begin{array}{c}0 \\
\text { Volt } \\
(\mathrm{ml})\end{array}$ & $\begin{array}{c}12 \\
\text { Volt } \\
(\mathrm{ml})\end{array}$ & $\begin{array}{c}16 \\
\text { Volt } \\
(\mathrm{ml})\end{array}$ & $\begin{array}{c}\text { Selisih } \\
0 \mathrm{~V} \\
\text { dengan } \\
12 \mathrm{~V}\end{array}$ & $\begin{array}{c}\text { Selisish 0 V } \\
\text { dengan 16 V }\end{array}$ \\
\hline 1 & 35 & 20 & 25 & 15 & 10 \\
\hline 2 & 35 & 25 & 25 & 10 & 10 \\
\hline 3 & 30 & 20 & 20 & 10 & 10 \\
\hline 4 & 35 & 20 & 25 & 15 & 10 \\
\hline 5 & 30 & 25 & 20 & 5 & 10 \\
\hline $\begin{array}{c}\text { Rata- } \\
\text { rata }\end{array}$ & 33 & 22 & 23 & $\begin{array}{c}11 \\
(33 \%)\end{array}$ & $10(30 \%)$ \\
\hline
\end{tabular}

Tabel 1 :. Tabel hasil penelitian

*Catatan : Panjang lintasan $2200 \mathrm{~m}$ dengan kecepatan konstan $30 \mathrm{~km} / \mathrm{jam}$.

Dengan pemberian voltase pada aliran input bahan bakar dapat menghemat dalam penggunaan bahan bakar. Hasil yang diperoleh dari pengujian yang dilakukan, pengaruh pemberian voltase terhadap konsumsi bahan bakar.

Pada bab ini menjelaskan pengaruh pemberian elektron pada aliran input bahan bakar terhadap penghematan bahan bakar dan beberapa pengaruh yng dapat mengakibatkan terjadinya pembakaran lebih sempurna. Uji coba yang dilakukan dengan jarak tempuh 2200 meter dengan jalan mendatar dan kecepatan konstan 30 $\mathrm{km} / \mathrm{jam}$. Hal ini dilakukan dikarenakan agar pada saat uji coba didapatkan data yang tetap dengan dapat dilihat perubahanperubahan yang terjadi pada saat dilakukan uji coba tanpa voltase, dengan voltase 12 volt dan 16 volt.

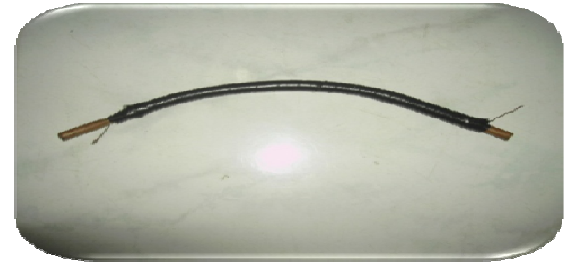

Gambar 4.1 : Gbr Pipa aliran Bahan bakar

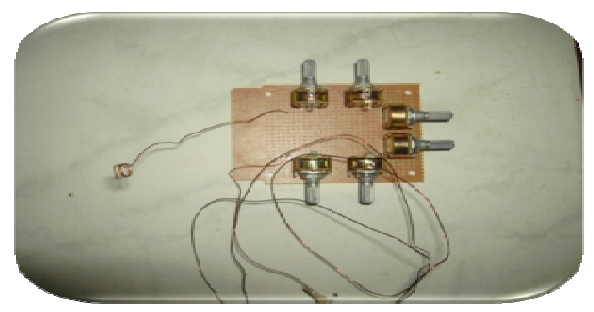

Gambar 4.2: Rangkaian Potensio

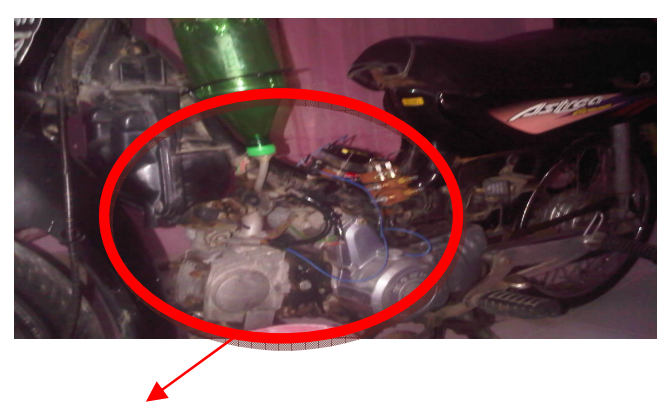

Gambar 4.3 : Rangkaian yg telah di pasang pada kendaraan.

\section{Kesimpulan dan Saran \\ 4.1 Kesimpulan}

1. Alat penghemat bahan bakar dengan panjang pipa aliran bahan bakar 24 $\mathrm{cm}$ memberikan pengaruh nyata terhadap konsumsi bahan bakar.

2. Alat penghemat bahan bakar dengan panjang pipa aliran bahan bakar 24 $\mathrm{cm}$ yang di aliri dengan tegangan 12 volt dapat menghemat konsumsi bahan bakar sampai dengan 33\%.

3. Alat penghemat bahan bakar dengan panjang pipa aliran bahan bakar 24 $\mathrm{cm}$ yang di aliri dengan tegangan 16 volt dapat menghemat konsumsi bahan bakar sampai dengan 30\%.

4. Dengan di aliri tegangan 12 volt memberikan penghematan bahan 
bakar lebih efektif dari pada aliran yang di aliri tegangan 16 volt.

5. Dengan penginjeksian elektron aliran bahan bakar maka terjadi ikatan kimia yang lebih baik yang dapat mengakibatkan bahan bakar bensin lebih reaktif sehingga terjadi penurunan kadar hidrokarbon (HC) pada gas buang kendaraan bermotor.

\subsection{Saran}

Untuk mengembangkan penelitian ini diperlukan penelitian lanjutan yang sedang dirancang untuk dilaksanakan :

1. Mencoba dengan panjang pipa aliran input bahan bakar yang lebih panjang untuk mengetahui panjang optimal yang dapat digunakan untuk mendapatkan penurunan emisi gas buang yang maksimal.

2. Mencoba merubah bahan dari pipa aliran input bahan bakar dengan bahan yang memiliki sifat konduktor yg lebih tinggi.

3. Mencoba untuk merubah dari design agar jauh lebih aman dan nyaman.

\section{Daftar Pustaka}

1. Arifin, Zainal., Sukoco (2009), Pengendalian Polusi Kendaraan. Yogyakarta : Alfabeta.
2. Sarwono, Jonathan (2006), Analisis Data Penelitian Menggunakan SPSS, Yogyakarta : CV. Andi Offset.

3. Srikandi, Fardiaz,1992, "Polusi Air \& Udara", Paniseus,

4. Wardhana Arya, Wisnu , (2007), Dampak Pencemaran Lingkungan. Yogyakarta : CV. Andi Offset.

5. Arends, BPM, Beren Schot, H. (1980). Motor Bensin, Jakarta : Penerbit Erlangga.

6. Soenata, Nakoela. (2002). Motor Serba Guna. Jakarta : Pradnya Paramita.

7. DR. J.F. Gabriel (2001). Fisika Lingkungan. Jakarta : Hipokrates.

8. Fessenden \& Fessenden (1992) Kimia Organik. Jakarta : Erlangga

9. Hart, Craine (2003). Kimia Organik Suatu Kuliah Singkat. Jakarta : Erlangga

10. Douglas C.Giancoli (1999). Fisika Jilid 2. Jakarta : Erlangga.

11. Darmono (2006). Lingkungan Hidup dan Pencemaran, Jakarta ; Penerbit UI 